\title{
Calcium Oxalate Crystal Yield in Various Gravity Environments
}

Riann J. Egusquiza ${ }^{1}$, Robert Benjamin Runyon ${ }^{2}$, Jordan Ringel ${ }^{1}$, Craig W.C. Seber ${ }^{3}$, Gonzalo Leyva ${ }^{4}$, Jose Correa $^{5}$, Coulibaly Datoliban Roland ${ }^{5}$, Mujahid Umar ${ }^{2}$, Ming Xiao ${ }^{6}$, John T. Bushoven ${ }^{3}$, and Joy J. Goto ${ }^{1}$

${ }^{1}$ Department of Chemistry, ${ }^{2}$ Department of Mechanical Engineering, ${ }^{3}$ Department of Plant Science, ${ }^{4}$ Department of Electrical Engineering, ${ }^{5}$ Department of Civil and Geomatics Engineering, California State University, Fresno, CA, ${ }^{6}$ Department of Civil and Environmental Engineering, Pennsylvania State University, University Park, PA 16802

\section{ABSTRACT}

An experimental chamber and handmanipulated syringe apparatus were designed, tested, and utilized to assess calcium oxalate crystal yield in Terrestrial- $g(1 \mathrm{~g})$, micro- $g$ (0.01 $g)$, Lunar-g $(0.16 g)$, and Martian-g (0.38 g). Aqueous solutions of calcium chloride $(100 \mathrm{mM})$ and oxalic acid (200 $\mathrm{mM})$ were mixed to precipitate calcium oxalate crystals. Gravitational differences were hypothesized to result in differences in the yield of crystal formation. These data are essential for efforts to better understand the correlation between calcium oxalate crystal formation and the production of kidney stones often associated with long-term space missions. The analyses of crystal formation produced in the micro- $g(\cong 0.01 \mathrm{~g})$ conditions of this study suggest that calcium oxalate monohydrate formation yield is slightly greater than those produced in Terrestrial- $g$ conditions.

Key words: Calcium Oxalate; Microgravity; Kidney Stone; Secondary Plant Metabolite; Oxalic Acid; Calcium Chloride

Correspondence to: Joy J. Goto, Ph.D.

California State University, Fresno

Department of Chemistry

2555 East San Ramon Avenue, MS SB70

Fresno, CA 93740

Telephone: 559-278-2530

E-mail: jgoto@csufresno.edu

\section{BACKGROUND}

Calcium oxalate $\left(\mathrm{CaC}_{2} \mathrm{O}_{4}\right.$ or $\left.\mathrm{CaOx}\right)$ is an insoluble crystal, formed as a precipitate of calcium and oxalate ions, and is produced in both plants and animals. In plants, $\mathrm{CaOx}$ has multiple functions including: (1) defense from herbivores, causing irritation and burning sensations when consumed (Korth et al., 2006), (2) critical structural support in sclereids and cell membranes, (3) gravity perception in the form of statoliths (Audus, 1962), and (4) control of $\mathrm{pH}$, ionic, and osmotic fluctuations (Raven et al., 2005). In animals, $\mathrm{CaOx}$ is generally considered pathological and often associated with renal edema and kidney stone formation (Dempsey et al., 1960). Most human diets are rich in oxalates (e.g., green leafy vegetables - spinach, chard, rhubarb, broccoli) and calcium (e.g., dairy products - milk, yogurt, cheese), and other metabolites (e.g., purine, uric acid) and toxins (e.g., ethylene glycol) that can contribute to renal pathologies (Franceschi and Horner, 1980; Hagler and Herman, 1973). Humans prevent $\mathrm{CaOx}$ accumulation by normal excretion (26-46 mg/day) of oxalate in urine. However, metabolic dysho-meostasis including increased urinary oxalate (hyperoxaluria), uric acid (hyperuricosuria), phosphorous (hyperphosphaturia), and decreased urinary excretion of citrate (hypocitraturia), can all lead to an increased risk of kidney stone formation in humans (Zerwekh, 2002). 
Astronauts on long- and short-term spaceflights under microgravity often exhibit progressive and continuous negative calcium balance from bone loss (Miyamoto et al., 1998; Whedon and Rambaut, 2006), increased urinary calcium and $\mathrm{pH}$, and decreased urine volume (Whitson et al., 1997; Whitson et al., 1999; Whitson et al., 2001). Decalcification of bones during extended-duration spaceflights has been demonstrated to occur at a rate of $\sim 300 \mathrm{mg}$ of calcium/day (Smith et al., 2005). These biological factors can all contribute to the formation of harmful kidney stones in astronauts (Drinnan and Begougne de Juniac, 2013). Our hypothesis was that microgravity induces the formation of a preferred crystal structure (either mono or dihydrate calcium oxalate), and there could be a difference in total crystal concentration when formed under various gravitational accelerations.

It has long been known that calcium oxalate can form either as a monohydrate (COM) or a dihydrate (COD) (Equations 1-2). The COM crystals, also known as whewellite, vary in size and morphology, and may have a spindle, oval and dumbbell, or elongated hexagonal structure (Monje and Baran, 2002). The COD crystals, or weddellite, are octahedral (square bipyramid) with eight faces and an envelope morphology. Most kidney stones contain about twice as much COM as COD (Petrova et al., 2004; Wesson et al., 1998). The COM crystal structures are found to have a high affinity for the surface of renal tubule cells (Peerapen and Thongboonkerd, 2011), suggesting that crystalline morphology and size may influence their deleterious effects.

Equation (1): Calcium oxalate monohydrate (COM)

$$
\mathrm{H}_{2} \mathrm{C}_{2} \mathrm{O}_{4}(\mathrm{aq})+\mathrm{CaCl}_{2}(\mathrm{aq})+\mathrm{H}_{2} \mathrm{O}(\mathrm{l}) \rightarrow \mathrm{CaC}_{2} \mathrm{O}_{4} \cdot \mathrm{H}_{2} \mathrm{O}(\mathrm{s})+2 \mathrm{H}^{+}(\mathrm{aq})+2 \mathrm{Cl}^{-}(\mathrm{aq})
$$

Equation (2): Calcium oxalate dihydrate (COD)

$$
\mathrm{H}_{2} \mathrm{C}_{2} \mathrm{O}_{4}(\mathrm{aq})+\mathrm{CaCl}_{2}(\mathrm{aq})+2 \mathrm{H}_{2} \mathrm{O}(\mathrm{l}) \rightarrow \mathrm{CaC}_{2} \mathrm{O}_{4} \cdot 2 \mathrm{H}_{2} \mathrm{O}(\mathrm{s})+2 \mathrm{H}^{+} \text {(aq) }+2 \mathrm{Cl}^{-} \text {(aq) }
$$

\section{MATERIALS AND METHODS}

Initially, calcium chloride $\left(\mathrm{CaCl}_{2}\right)$ and sodium oxalate $\left(\mathrm{Na}_{2} \mathrm{C}_{2} \mathrm{O}_{4}\right)$ were used to form either $\mathrm{COM}$ or COD crystals; see Figure 1 . This equimolar, equal-volume mixture yielded a precipitate that was too small to readily visualize, resulting in replacement of sodium oxalate with oxalic acid $\left(\mathrm{H}_{2} \mathrm{C}_{2} \mathrm{O}_{4}\right)$, and mixed at three concentrations (equimolar, 100, or $200 \mathrm{mM}$ ). Solutions were allowed to mix for several minutes, followed by vacuum filtering. Resulting crystals were ovendried, mounted on slides, and visualized using light microscopy (Nomarski DIC 40x and 100x, Olympus BX45 with charge-coupled device (CCD) camera). Figure 2A shows the resulting mixture of COM (right-pointing arrow) and COD (left-pointing arrow) crystals from equimolar concentrations of calcium chloride and oxalic acid.

While yields were relatively high, the methodology was further refined to favor formation of predominantly COM crystals.
Figures 2B and 2C show the druse-like COM crystals formed from mixing equal volumes of $100 \mathrm{mM}$ calcium chloride (pH 5.64) and $200 \mathrm{mM}$ oxalic acid (pH 1.48) (reagent grade, Fisher Scientific). All solutions were prepared with double-distilled water using volumetric glassware. The vacuum filtration method was used to collect the crystals in Figures 2B and 2D; the in-flight apparatus was used for crystals in Figure 2C. Higher concentrations of calcium chloride (200 $\mathrm{mM})$ and oxalic acid (100 mM) favored the formation of predominantly COD (Figure 2D). The $100 \mathrm{mM}$ calcium chloride and $200 \mathrm{mM}$ oxalic acid mixture was the standard solution used in this study to model COM crystal formation (that most associated with kidney stones) in the microgravity in-flight experiments.

The in-flight experiments were conducted at an altitude 26-36,000 feet above the Gulf of Mexico aboard NASA's Boeing-727 aircraft, officially nicknamed the "The Weightless Wonder" based at Ellington Field, Houston, Texas. Eight California State University, Fresno 


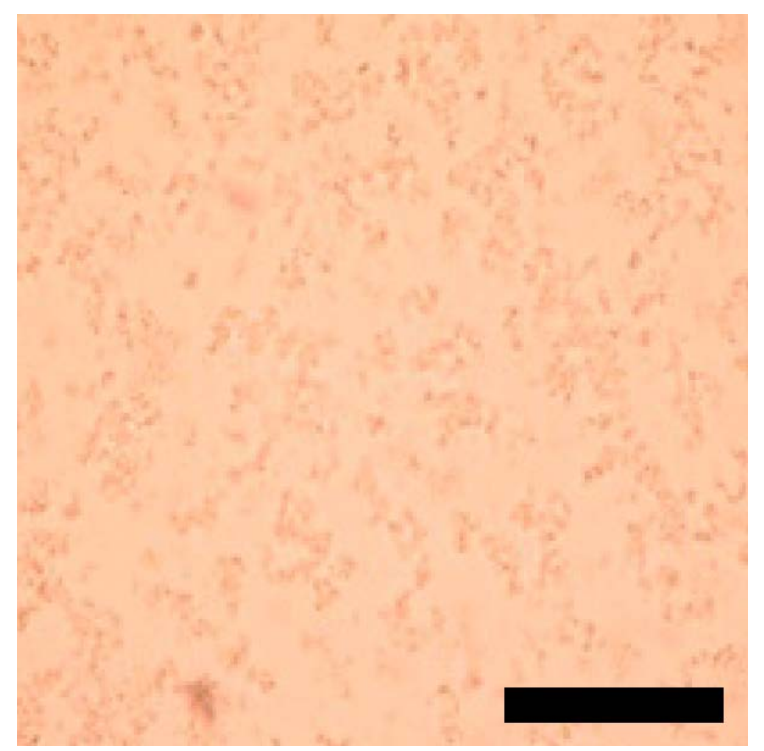

Figure 1. Preliminary crystals formed by mixing sodium oxalate and calcium chloride. The scale bar represents $100 \mu \mathrm{m}$.

undergraduates participated in the design and data collection as a part of the NASA-Reduced Gravity Student Flight Opportunities Program. Performing up to 30 parabolic maneuvers per flight, this flight pattern produced 30 segments of microgravity $(0.01 \mathrm{~g})$ lasting $\sim 25-30$ seconds, and one to two segments of Lunar gravity $(0.16 \mathrm{~g})$, and Martian gravity $(0.38 \mathrm{~g})$, also lasting $\sim 30$ seconds (Figure 3). Two flights were conducted over two successive days; the flight number and the associated crystal yields are reported. Crystal precipitation reactions were conducted at each of these gravity environments using an apparatus that consisted of two $10 \mathrm{~mL}$ syringes, a three-way luer stopcock, and a $0.45 \mu \mathrm{m}$ Swin-Lok filter holder (Fisher Scientific) (Figure 4). One syringe contained $2 \mathrm{~mL}$ of $200 \mathrm{mM}$ oxalic acid and the other syringe contained $2 \mathrm{~mL}$ of $100 \mathrm{mM}$ calcium chloride. During each of the 25-30 seconds of microgravity $(0.01 \mathrm{~g})$, Lunar gravity $(0.16 \mathrm{~g})$, or Martian gravity $(0.38 \mathrm{~g})$ flight segments, oxalic acid was injected into the adjoining syringe containing calcium chloride. The luer stopcock was turned to block solution transfer to one syringe after 5 seconds, to allow for precipitate formation, to facilitate the collection of the resulting crystals on the filter below the apparatus, and to subsequently void remaining solution volume into the attached waste bag. The chamber allowed for three flight team members to simultaneously manipulate each of the syringe apparati (Figure 4 and Figure 5, top panel). Flight safety conditions mandated that studentdesigned/built equipment required for each precipitation reaction be securely housed directly below the syringe apparatus (Figure 5). Filters were removed from the apparatus upon aircraft return to Ellington Field, dried, weighed, and were stored in glass vials for subsequent structure characterization via light microscopy upon return to California State University, Fresno.

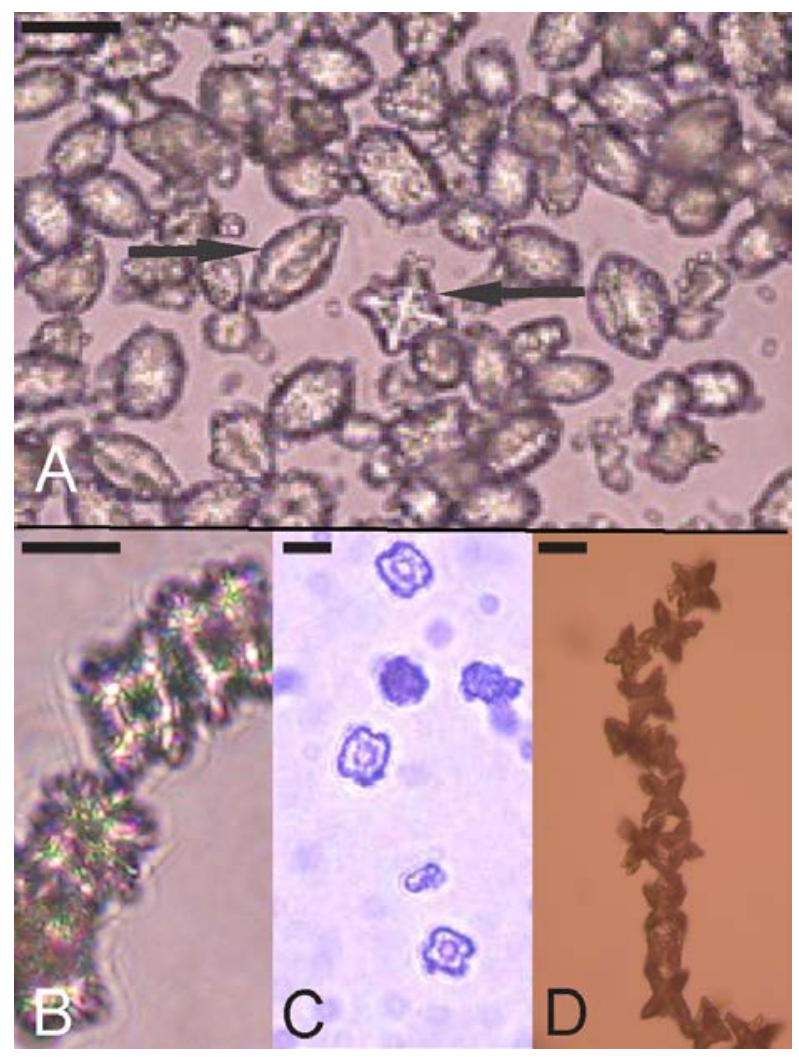

Figure 2. Examples of crystals formed with: (a) Equimolar concentrations of oxalic acid and calcium chloride. The COM elongated, 'orzoshaped' crystalline form is indicated by the rightpointing arrow and the COD octagonal, 'envelopeshaped' crystalline form is indicated by the leftpointing arrow. The COM form is more abundant in this equimolar mixture; (b) $200 \mathrm{mM}$ oxalic acid and $100 \mathrm{mM}$ calcium chloride collected using vacuum filtration; (c) Same reagent conditions as in Figure 2B, except synthesized in the luer lock 3-way syringe apparatus; (d) $100 \mathrm{mM}$ oxalic acid and 200 mM calcium chloride. Each scale bar represents 10 $\mu \mathrm{m}$. 


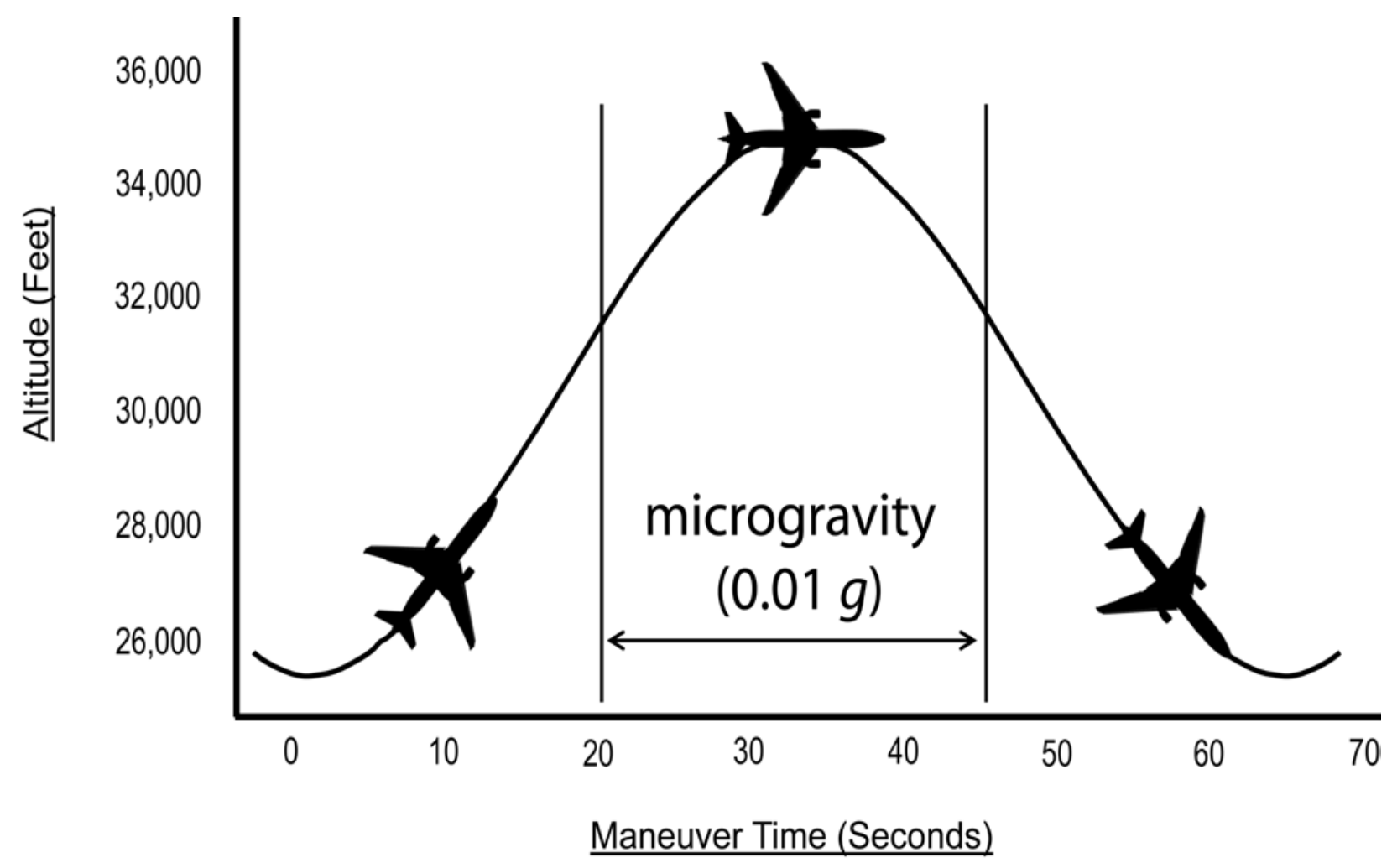

Figure 3. The parabolic flight path of the NASA Zero-G ("Weightless Wonder") aircraft.

The self-contained in-flight experimental chamber was designed using SolidWorks and constructed of an aluminum frame $(1.27 \mathrm{~m}$ long $\times$ $0.508 \mathrm{~m}$ wide $\times 0.762 \mathrm{~m}$ tall), lined with siliconsealed Lexan panels on all sides, and a top latched door (Figures 4 and 5). The chamber interior contained three separated foam blocks (green in Figure 5) with cut-outs to house individual syringe apparatus and covered with two sliding panels to contain the syringes after use throughout the flight. The reaction waste-collection bag was secured at the bottom of the chamber and connected to the syringes via polytubing. Six gloved-access holes were cut into the sides of the chamber; allowing for each of three flight team members to have simultaneous access to the chamber interior during the flight. Chamber and in-flight securing strap integrity were analyzed using the finite element method and were submitted to and verified by NASA Johnson Space Center engineering staff.

\section{RESULTS}

The average mass of synthesized crystals from each of the gravity environments for each of the two successive flights are summarized in Table 1. Theoretical calculations based on the initial reactants/concentrations predicted a final mass of COM to be $\sim 30-60 \mathrm{mg}$. All of the inflight crystals appeared to be greater in mass than those formed under Terrestrial gravity $(1 \mathrm{~g})$. The average mass of crystals precipitated in microgravity were the highest (108-220 mg), followed by that under Lunar gravity (82-216 $\mathrm{mg}$ ), Martian gravity (69-194 mg), and lastly, Terrestrial gravity (70-77 mg). The relatively large variation in crystal mass obtained in each flight was likely due to the unavoidable manipulation of the syringe apparatus in the turbulent flight environment. 


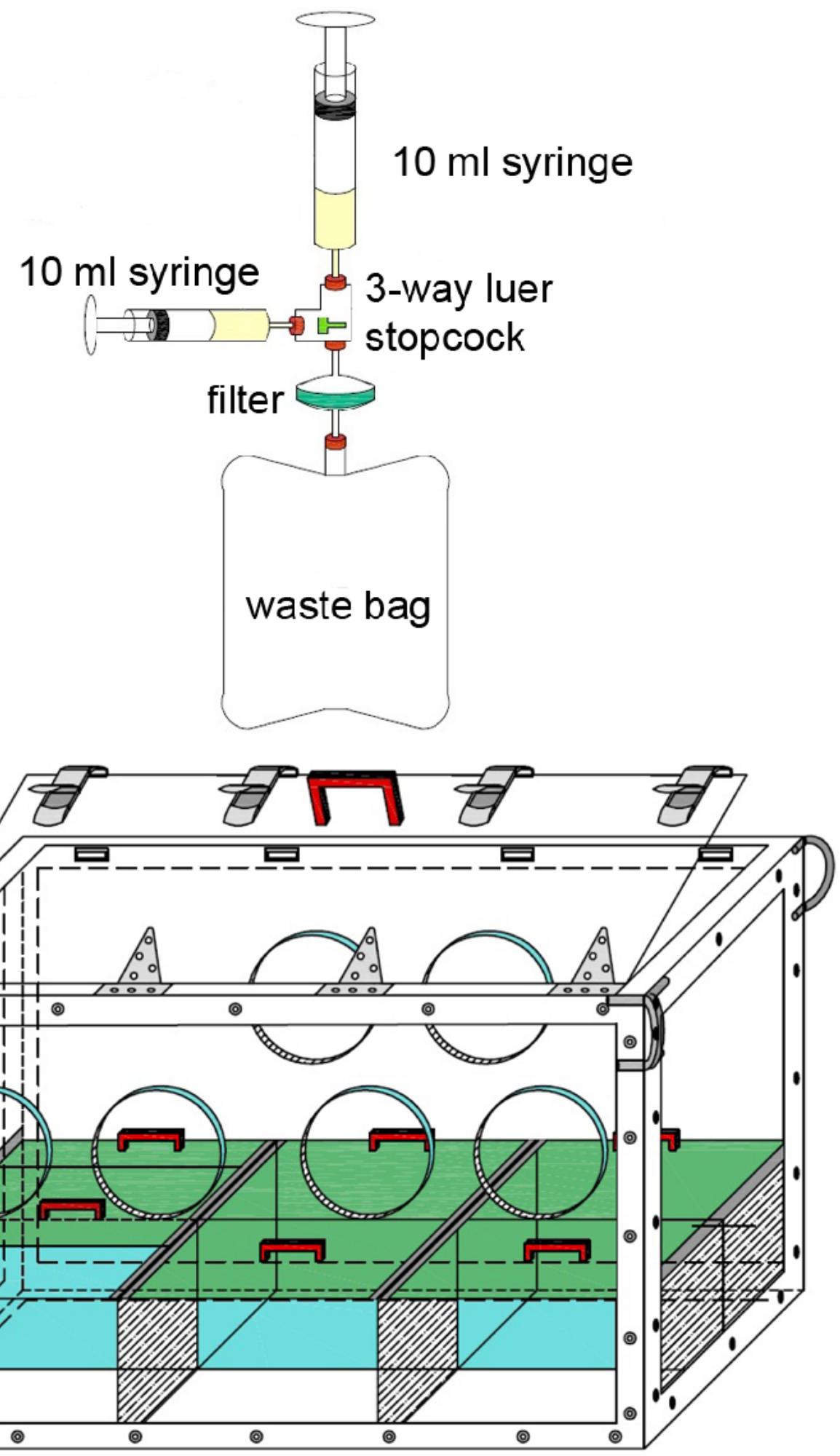

Figure 4. Schematic diagram of experimental rig. Top: Schematic drawing of the syringe apparatus used in the experiment. Bottom: CAD drawing of the experimental glove box for the formation and capture of crystals formed during the two flights. Glove box for experimental procedures and manipulations. 

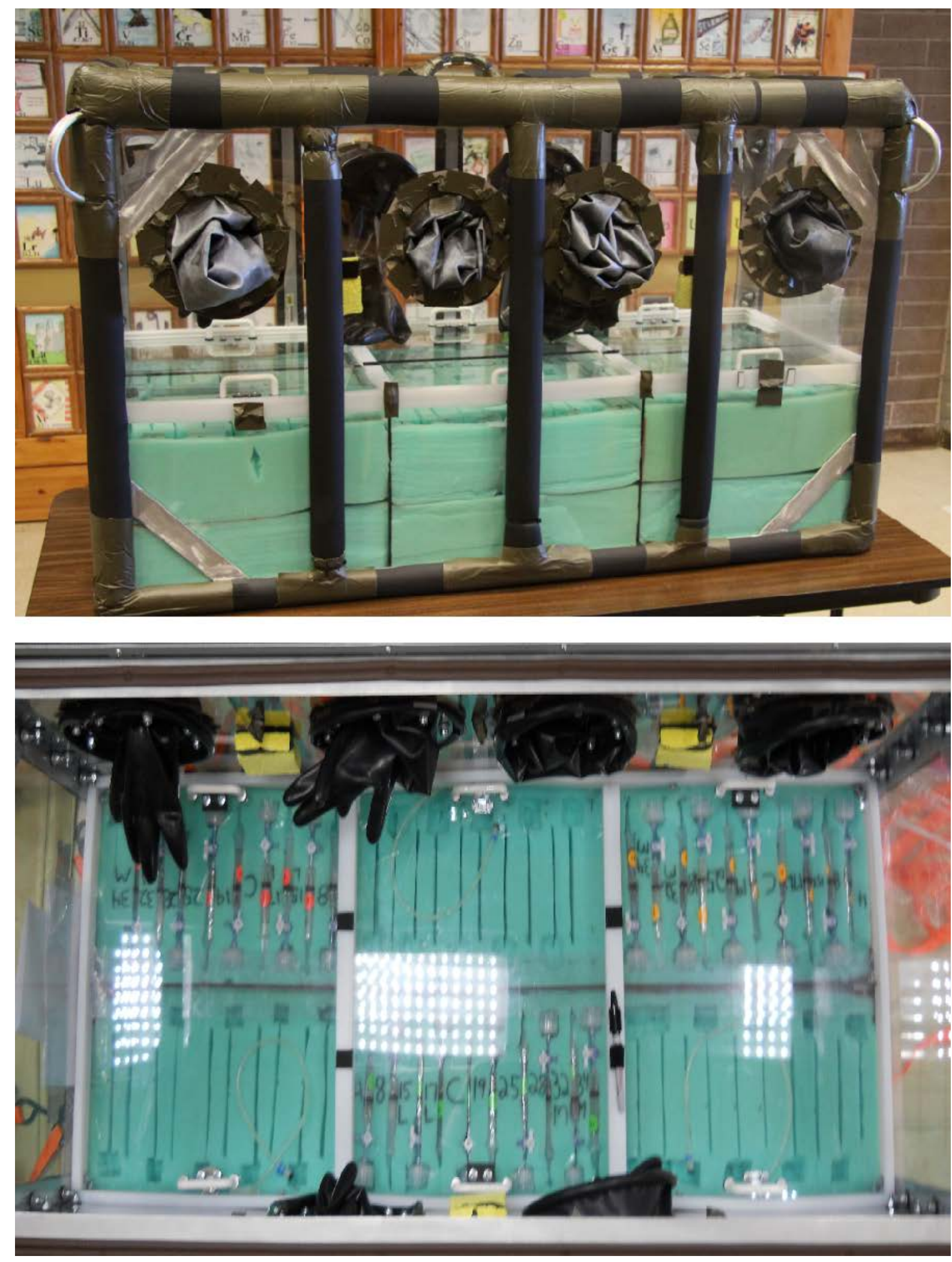

Figure 5. Photograph of the experimental rig. The image on the bottom shows the top view looking into the chamber. The layout of the syringes is shown for each of the three users. 


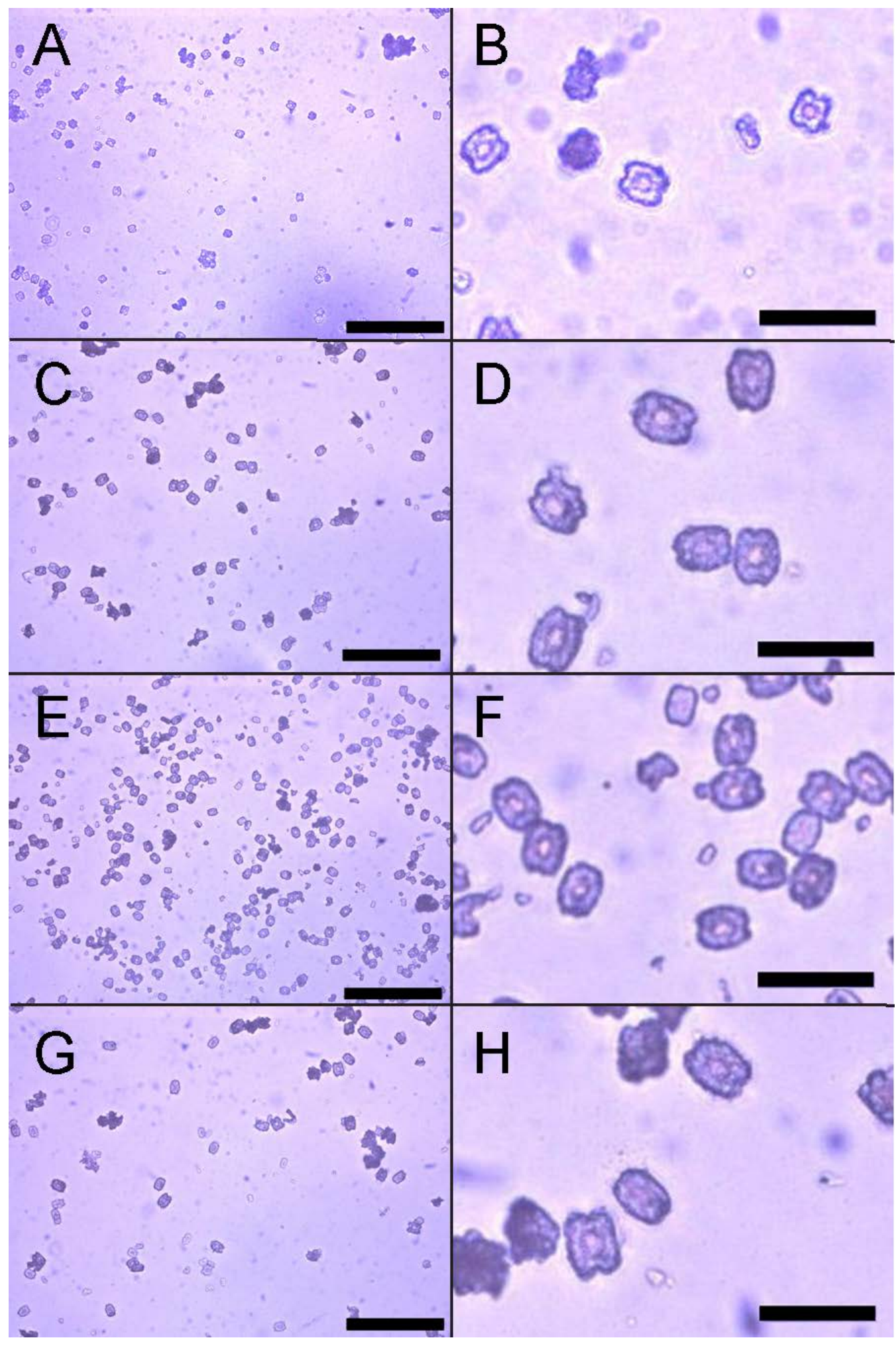

Figure 6. Microscope light images of calcium oxalate crystals formed under varying gravity conditions: 6A and 6B (Terrestrial gravity $(1 \mathrm{~g})$ ); 6C and 6D (microgravity $(0.01 \mathrm{~g})$ ); 6E and 6F (Lunar gravity (0.16 g)); and, $6 \mathrm{G}$ and $6 \mathrm{H}$ (Martian gravity $(0.38 \mathrm{~g})$ ). Scale bar is $100 \mu \mathrm{m}$ for $6 \mathrm{~A}, 6 \mathrm{C}, 6 \mathrm{E}$, and $6 \mathrm{G}$. Total magnification of $400 x$. Scale bar $=25 \mu \mathrm{m}$ for $6 \mathrm{~B}, 6 \mathrm{D}, 6 \mathrm{~F}$, and $6 \mathrm{H}$. 
Table 1. The average mass of synthesized crystals from each of the gravity environments (control, micro, lunar, and Martian), for each of the two successive flights. The number of trials (n) is given for each flight and gravity environment condition. The average mass (in gram units) and standard deviation (S.D.) are listed.

\begin{tabular}{|c|c|c|c|c|c|c|c|c|}
\hline Condition & \multicolumn{2}{|c|}{ Control (1 g) } & \multicolumn{2}{|c|}{$\operatorname{Micro}(\sim 0.01 \mathrm{~g})$} & \multicolumn{2}{|c|}{ Lunar (.16 g) } & \multicolumn{2}{|c|}{ Martian (0.38 g) } \\
\hline Flight \# & 1 & 2 & 1 & 2 & 1 & 2 & 1 & 2 \\
\hline $\begin{array}{l}\text { \# of trials (n) } \\
\text { for each flight }\end{array}$ & 2 & 1 & 12 & 14 & 4 & 6 & 3 & 6 \\
\hline $\begin{array}{c}\text { Average mass (g) } \\
\pm \text { S.D. }\end{array}$ & $\begin{array}{l}0.077 \\
\pm 0.03\end{array}$ & $\begin{array}{c}0.070 \\
\mathrm{n} / \mathrm{a}\end{array}$ & $\begin{array}{l}0.108 \\
\pm 0.04\end{array}$ & $\begin{array}{l}0.220 \\
\pm 0.10\end{array}$ & $\begin{array}{l}0.082 \\
\pm 0.04\end{array}$ & $\begin{array}{l}0.216 \\
\pm 0.07\end{array}$ & $\begin{array}{l}0.069 \\
\pm 0.03\end{array}$ & $\begin{array}{l}0.194 \\
\pm 0.06\end{array}$ \\
\hline
\end{tabular}

The images of the crystals formed in-flight and Terrestrial gravity $(1 \mathrm{~g})$ are shown in Figure 6 (A-H). The Terrestrial gravity (1 g) (control) crystals in Figures 6A and 6B are characteristic COM druse whewellites, resembling COMs naturally found in cacti (Monje and Baran, 2002), each $\sim 10-15 \mu \mathrm{m}$ in diameter. The crystals produced at microgravity $(0.01 \mathrm{~g})$ are shown in Figures 6C and 6D. The crystals formed under Lunar gravity $(0.16 \mathrm{~g})$ (Figures $6 \mathrm{E}$ and $6 \mathrm{~F}$ ) and Martian gravity $(0.38 \mathrm{~g})$ (Figures $6 \mathrm{G}$ and $6 \mathrm{H})$ also present the characteristic COM druse morphology.

\section{DISCUSSION}

The calcium oxalate crystals formed under microgravity showed only slight differences in crystal size, but not in morphology, when compared to crystals formed under Terrestrial gravity $(1 \mathrm{~g})$. Our hypothesis that the $\mathrm{CaOx}$ crystal yield should be greater in microgravity was confirmed in this study, as the yield of COM crystals in microgravity was slightly greater than that under Terrestrial gravity $(1 \mathrm{~g})$.

The thermodynamically preferred state of $\mathrm{CaOx}$ is the COM structure, though the microgravity environment was hypothesized to influence the yield. The results of this study showed a slight increase in yield of COMs formed under microgravity and these data may provide for a better understanding of kidney stone formation under such conditions. Studies using multiple concentrations of calcium chloride and oxalic acid are necessary to further characterize formation of the preferred structures. The kinetic parameters of each reaction performed in this study may also have had an effect, as the time period ( 10 seconds) of each gravity environment, particularly at microgravity, may not have been sufficient to fully reveal actual gravity effects on $\mathrm{CaOx}$ structure formation (Jung et al., 2011). A longer reaction time may be necessary to fully model crystal formation in the microgravity environment found in long-term space missions, and should be incorporated in subsequent in-flight studies. Conducting these precipitation reactions over a span of hours, or even days in a simulated or actual microgravity environment (with multiple reaction concentrations and an automated mixing system), is the next logical step for our undergraduate student team investigation.

It should also be noted there may be major differences between synthetic in vitro and in vivo formed biogenic crystals (da Costa et al., 2009). We cannot rule out other biological factors (e.g., nanobacteria in the human body or other urinary molecules) (Çiftçioglu et al., 2005) that likely influence the formation and subsequent damage caused by $\mathrm{CaOx}$ crystals. Our follow-up studies will include infrared spectroscopy (IR), scanning electron microscopy (SEM), and x-ray diffraction (XRD) to confirm the morphology of the precipitated crystals formed in this study and will likely also include use of fluorescence techniques (Hernandez-Santana et al., 2011) to identify the presence/absence of calcium containing crystals. These data are essential for the success of future long-term manned space exploration missions.

\section{ACKNOWLEDGEMENTS}

We would like to thank the following for their support (logistical, scientific, and financial) throughout this project: Dr. John Allred, NASA 
Johnson Space Center; NASA Reduced Gravity Program Team (Sara Malloy, Doug Goforth, Robert Roe, Dominic Del Rosso, Fernando Zumbado); The "Grant Us Space" Program, Marlene Miyasaki, United Cerebral Palsy, National Raisin Company, Chico's Women's Clothing, Azteca Milling Corporation, Precision Plastics, Rand Welding and Fabrication; California State University, Fresno (Lyles College of Engineering-Dean Ram Nunna; College of Science and Mathematics-Dean Andrew Rogerson; Jordan College of Agricultural Science and Technology-Dean Charles Boyer, California State University-Louis Stokes Alliance for Minority Participation (CSU-LSAMP, NSF \#HRD-1302873) and Office of Undergraduate Studies at California State University, FresnoDean Dennis Nef; Faculty-Sponsored Student Research Awards from the College of Science and Mathematics and Undergraduate Research Grants from the Office of Undergraduate Studies; Fresno State Associated Students Inc., Instructionally Related Activities.

\section{REFERENCES}

Audus LJ (1962) The mechanism of the perception of gravity by plants. Symposia Society for Experimental Biology 16: 197-226

Çiftçioglu N, Haddad SR, Golden DC, Morrison RD, McKay D (2005) A potential cause for kidney stone formation during spaceflights: enhanced growth of nanobacteria in microgravity. Kidney International 67: 483491

da Costa LM, Tronto J, Constantino VRL, Fonseca MKA, Oliveria AP, da Costa MR (2009) Extraction and concentration of biogenic calcium oxalate from plant leaves. Revista Brasileira de Ciência do Solo 33: 729-733

Dempsey EF, Forbes AP, Melick RA, Henneman PH (1960) Urinary oxalate excretion. Metabolism 9: 52-58

Drinnan NRT, Begougne de Juniac A (2013) The effects of microgravity on the urological system: a review. Journal of Clinical Urology 6: $391-394$

Franceschi RV, Horner TH (1980) Calcium oxalate crystals in plants. Botanical Review 46(4): 364-411
Hagler L, Herman RH (1973) Oxalate metabolism. I. American Journal of Clinical Nutrition 26: 758-765

Hernandez-Santana A, Yavorsky A, Loughran ST, McCarthy GM, McMahon GP (2011) New approaches in the detection of calciumcontaining microcrystals in synovial fluid. Bioanalysis 3(10): 1085-1091

Jung T, Kim JN, Kim WS, Choi CK (2011) Study of polymeric additive effect on calcium oxalate dihydrate crystal growth using realtime atomic force microscopy. Journal of Crystal Growth 327: 167-172

Korth KL, Doege SJ, Park SH, Goggin FL, Wang Q, Gomez SK, Liu G, Jia L, Nakata PA (2006) Medicago truncatula mutants demonstrate the role of plant calcium oxalate crystals as an effective defense against chewing insects. Plant Physiology 141: 188195

Miyamoto A, Shigematsu T, Fukunaga T, Kawakami K, Mukai C, Sekiguchi C (1998) Medical baseline data collection on bone and muscle change with spaceflight. Bone 22(5): 79S-82S

Monje PV, Baran EJ (2002) Characterization of calcium oxalates generated as biominerals in cacti. Plant Physiology 128: 707-713

Peerapen P, Thongboonkerd V (2011) Effects of calcium oxalate monohydrate crystals on expression and function of tight junction of renal tubular epithelial cell. Laboratory Investigation 91: 97-105

Petrova EV, Gvozdev NV, Rashkovich LN (2004) Growth and dissolution of calcium oxalate monohydrate (COM) crystals. Journal of Optoelectronics and Advanced Materials 6(1): 261-268

Raven HP, Evert FR, Eichhorn ES (2005) Biology of Plants, Seventh edn, pp 46, 471, 515. New York: WH Freeman and Company

Smith SM, Wastney ME, O’Brien KO, Morukov BV, Larina IM, Abrams SA, Davis-Street JE, Oganov V, Shackelford LC (2005) Bone markers, calcium metabolism, and calcium kinetics during extended-duration spaceflight on the Mir space station. Journal of Bone and Mineral Research 20(2): 208-218

Wesson JA, Worcester EM, Wiessner JH, Mandel NS, Kleinman JG (1998) Control of calcium oxalate structure and cell adherence by 
urinary macromolecules. Kidney International 53: $952-957$

Whedon GD, Rambaut PC (2006) Effects of longduration spaceflight on calcium metabolism: review of human studies from Skylab to present. Acta Astronautica 58: 59-81

Whitson PA, Pietrzyk RA, Morukov BV, Sams CF (2001) The risk of renal stone formation during and after long duration spaceflight. Nephron 89: 264-270
Whitson PA, Pietrzyk RA, Pak CYC (1997) Renal stone risk assessment during space shuttle flights. The Journal of Urology 158(6): 23052310

Whitson PA, Pietrzyk RA, Sams CF (1999) Spaceflight and the risk of renal stones. Journal of Gravitational Physiology 6(1): 8788

Zerwekh JE (2002) Nutrition and renal stone disease in space. Nutrition 18: 857-863 